\title{
An exploration of the family resilience needs of a rural community in South Africa: a sequential explanatory mixed methodological study design
}

\author{
Serena Ann Isaacs, Nicolette V. Roman and Shazly Savahl
}

\begin{abstract}
The aim of the study is to identify and explore family resilience needs in a rural community in the West Coast region of South Africa. An explanatory mixed methodological sequential design was implemented. Firstly, Sixbey's (2005) Family Resilience Assessment Scale, was employed to conduct the quantitative assessment via a door-to-door sample of convenience identified with the assistance of a local non-governmental organisation. Of the 656 participants, $39.8 \%$ were male and 60.2\% were female, with an average age of 37.90 years (standard deviation 13.92). Secondly, four focus groups involving 27 community participants provided qualitative data. Results from the quantitative assessment show that family connectedness and utilising social and economic resources were the lowest scoring, and belief systems the highest scoring, dimensions in family resilience. Based on the quantitative findings and the discussions, three thematic categories emerged: community and family challenges; community belief systems; and current family functioning and organisational patterns. A number of families and groups within the community were able to provide feedback, recommendations and work collaboratively in this study. This contributed to the argument we make for the transformative mixed methods paradigm that is discussed. This study provides further insight into the theory of family resilience.
\end{abstract}

\section{Background}

The family is regarded as the core structure in developing healthy childhood outcomes (Schrodt and Ledbetter 2007). Nevertheless, these outcomes can be negatively influenced by exposure to different kinds of adversity the family can experience (Walsh 2003, 2006, 2012, 2016) such as divorce, crime, violence, physical and mental illness, unemployment and poverty (Lietz 2013; Torres Fernandez et al. 2013). Such exposure can have a severe effect on the stability of family life (Blair and Raver 2012). However, these kinds of adversity may not necessarily contribute to family depredation; a sense of familial connectedness and wellbeing may on occasion be engendered as a result of adversity (Walsh 2016). The ability not only to withstand but also to rebound from adversity is a characteristic of family resilience (Walsh 2003). A family resilience perspective enhances our understanding of family functioning and is viewed as being nested within varying structures over time, in the context of 
adversity (Black and Lobo 2008; Walsh 2012).

The complexity of family dynamics can be seen in each family's unique structure, available resources and context (Dimech 2014). Together, these various structures, traits, resources and contexts function as a system that is unique to each family, affecting and influencing other systems within which the members live. When a family experiences resource constraints (such as financial and social means, communication, problem-solving skills, connectedness etc.) to function, their focus may tend to fall more on daily survival rather than the growth or development of the family (Walsh 2016).

However, theoretically and empirically, it has been posited that the risk of this happening can be moderated by good relationships within the family of origin (Sobolewski and Amato 2005; Walsh 2006). For example, Sobolewski and Amato (2005) assessed the emotional wellbeing of children who experience prolonged exposure to economic hardship, by means of a longitudinal method. Their findings showed that economic hardship in the family of origin predicted marital discord and weaker parent-child relationships as well as making it more challenging to improve socio-economic stability. Prolonged low economic status was also shown to be particularly negative for adolescents, as their potentially adversely affected development has repercussions for their future families (Sobolewski and Amato 2005).

An example of a country with a history of prolonged low socio-economic stability for the majority of families and continue to face the effects of disparities is that of South Africa (Holborn and Eddy 2011; Poverty Trends in South Africa 2017). A far-reaching effect of apartheid in South Africa was the role that this policy played in engendering extreme disparity in socio-economic status and resources (Cornish- Jenkins 2016). Poverty Trends in South Africa (2017) reports that although poverty declined between 2006 (66.6\%) and 2011 (53.2\%), it has increased to $55.5 \%$ in 2015. Poverty has increased across all provinces, with the exception of Mpumalanga whose average consistently decreased between 2006 from $75 \%$ to $59.3 \%$ in 2015 .

According to Casale et al. (2013), the highest levels of material and social deprivation indices tend to be more apparent in rural than in metropolitan areas. The Poverty Trends in South Africa report (2017) showed the poverty gap between poorer people in rural versus urban areas in South Africa is significantly different. Whereas the poverty headcount in urban areas was $40.6 \%$ in 2015 , the percentage in rural areas was $81.3 \%$. Institutionalised racism and inequality has impeded the opportunities for disadvantaged people to accumulate capital (Narayan and Mahajan 2013). The unequal distribution of capital is especially prevalent in various communities across the country (Morris et al. 2012). The effects of concentrated poverty in these rural communities enhance their vulnerability to risks such as crime, violence, disease and limited access to social and economic networks (Philip et al. 2014), and cause stresses and strains upon the roles within families (Coley and Lombardi 2014; Perkins et al. 2013). For example, the inability to fulfil a wage-earning function as a result of unemployment and scarcity of employment opportunities can cause distress among caregivers (such as anxiety about the family's financial obligations). This situation has led to many

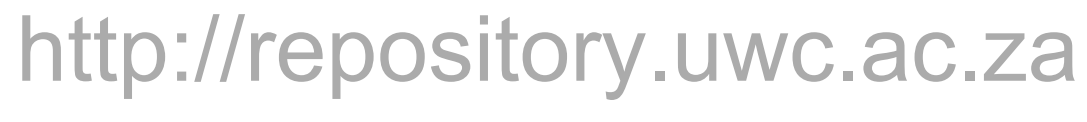


'skip-generation' - in which grandparents and grandchildren live in one household (Das \& Zimmer, 2015) - or single-parent households, as one or more care-givers are compelled to leave their homes to seek employment elsewhere in the country. This may also lead to inadequate, inconsistent or ineffective nurturing of children; poor control over children's behaviour; and lack of warmth and support from parents or primary caregivers (Ahmed 2 005; Banovcinova et al. 2014).

Still, it should be noted that even under difficult conditions the family can create the safest environment for its members' survival and can be described as the basic unit of a functioning society (Banovcinova and Levicka 2015). Given the importance of family functioning to the wellbeing of all members of the family unit (der Kinderen and Greeff 2003), it is important to focus on a family's strengths so that it is possible to understand how adversities can be faced, overcome and turned around (Seccombe 2002). Family resilience is defined as the ability of a family to address and overcome challenges they experience. (Walsh 2016). Resilience processes can enable transformation and foster empowerment (Vermeulen and Greeff 2015). This raises the question of whether or not each family has its own resilience threshold and with that prompted us to ask, is it possible to measure a family's resilience levels regardless of its circumstances?

\section{Conceptual Framework}

Families display resilience when they function optimally in three broad categories: shared belief systems, effective communication, and organisational patterns (Walsh 2003). Our belief systems influence our actions; and the consequences of those actions often serve to concretise further those beliefs (Walsh 2006). Belief systems include, but are not limited to, a family's ability to maintain a positive outlook, make meaning of their adversities (Black et al. 2014), and possess transcendental beliefs and spirituality (Walsh 2012). Shannon et al. (2013) also state that religion and spiritual beliefs can moderate the effects of adversity such as exposure to violence. They found that daily religious and spiritual practices and beliefs can protect adolescents from the negative effects of exposure to violence, and they support the use of spirituality by therapists in psychotherapy, especially when it is an important part of their clients' beliefs. Belief systems can also include the family's locus of control, i.e. their idea of causality or who is to be 'blamed' for a current event. Deep social, cultural and emotional roots anchor a family's beliefs (Walsh 2006). Greeff and Loubser (2008) explored various dimensions of spirituality in promoting family resilience in Xhosa-speaking people in South Africa. Further, religion and spirituality, as practised by their participants in ways such as prayer, belief in God's plan, and participating in religious activities, can be a protective and recovery-conducive resource, and should be accessed in times of crises. They further found that participants experienced transformation during times of crises, and attributed much of the transformation to their belief systems. Family beliefs are therefore important when considering family resilience. However, it is important to be cautious in assuming that all members will automatically share the same beliefs (Walsh 2006), as there may be dissonances in the practices within larger families and what individual members believe to be valid (Brelsford and Mahoney 2008). 
Communication is an essential aspect of family functioning (Bandura et al. 2011; Banovcinova and Levicka 2015). Samek and Reuter (2011) note that when families converse and try to achieve a shared reality, an overall family connectedness ensue. The effects of poor communication skills and their importance in family functioning and relationship building are welldocumented (Liermann and Norton 2016) and further compounded in families afflicted by economic instability (Banovcinova and Levicka 2015). Jonker and Greeff (2009) aimed to identify the family resilience factors present in a sample of South African participants who care for a family member suffering from mental illness. The authors found supportive communication was an important factor in encouraging family connectedness. Liermann and Norton (2016) confirm that including families in treatment programmes, especially when focus is given to family communication, leads to increased empathy and understanding and better family functioning, which further confirms the importance of good communication in families.

A family's organisational patterns further contribute to its functioning. Organisational patterns are stipulated by the leader of the family unit who enforces rules and provides structure as well as what Walsh (2006) refers to as a 'holding' or 'containing' environment for children. This dimension of family resilience encompasses a family's organisational flexibility, feelings of connectedness and their ability to utilise their available social and economic resources (Walsh 2003). Organisational patterns also refer to the flexibility of the family structure, the roles that each member plays within that structure, rules and accompanying rituals (Walsh 2006). Rituals and regular family activities also comprise a symbolic form of communication (Banovcinova and Levicka 2015), consolidating family interactions and connectedness. They support family communication and transfer values between family members (Miglorini et al. 2016). Crises such as parental divorce, death or unemployment often bring about change in routines and regular patterns. It is during crises that a family is able to provide a safe environment, which can lessen feelings of isolation or abandonment and increa se connectedness for its members. Mayberry et al. (2014) found that ensuring the continuation of routines and other family organisational activities created stable and predictable environments for children, even in the context of homelessness. Families can experience marginalisation on different levels: social, cultural and economic. When, for example, national policies do not take into account family wellbeing, major economic downturns can lead to isolation or marginalisation of the family (Seccombe 2002). Mobilising social and economic resources that families have access to can enhance family functioning (Sobolewski and Amato 2005).

Healthcare practitioners can have an important role to play in assisting families in gaining access to resources. However, it cannot fall solely upon healthcare practitioners and other professionals to mobilise these resources. There are resources and structures that only officials and policymakers can effectively address. Therefore, from a family resilience perspective, it is also necessary to consider the existing barriers to developing family strengths (Walsh 2016).

In order to address the aim of the study, given the conceptual framework, we noted that when exploring family resilience, a single methodological technique (such as a questionnaire or 
interview only) might not be a sufficiently comprehensive approach. A mixed-method technique may be more appropriate, especially since in a family resilience assessment as family processes cannot be adequately described if measured in one way only (DeHaan et al. 2015). Therefore, an explanatory mixed methodological sequential design was implemented for this study. Although the study is not classified as longitudinal, it aims to explore the quantitative findings in somewhat more depth by adding a qualitative dimension. Accordingly, the aim of the present study was to identify and explore the resilience needs of families living in a low- income/disadvantaged rural community in the West Coast region of South Africa.

\section{Method}

\section{Research Design}

An explanatory mixed methodological sequential design was implemented for this study. According to Ivankova et al. (2006), this design has two distinct and sequential phases. As discussed, Walsh's $(2006,2016)$ framework of family resilience compromises three major psychological dimensions with differing and nuanced family and wider community-level processes. In order to identify the 'needs' of families, the Family Resilience Assessment Scale (FRAS) was administered to family members across the community. The information, collected and analysed, provided a general understanding of the research problem, in this case, the family resilience needs and so informed the second, qualitative stage which builds upon the first (Ivankova et al. 2006). Therefore, the results of the quantitative phase provided the basis for the discussions in the qualitative phase. The qualitative stage ('Phase 2: Qualitative Assessment') was necessary in understanding the 'community definitions' (Wood 2016, p.1) of the family resilience dimensions found to be problematic, but the researcher was also able to gain further input on the research process; thus also ensuring space for adequate reflection through the process (Wood 2016). The first author had open and continuous dialogue between the co-authors, the NGO and its participants.

Windsor (2013) argues that involving community stakeholders in research studies furthers the development of interventions and services. The director and staff of the NGO and the primary author worked in close collaboration since the project's conceptualisation. The NGO provides social services to the community, such as weekly narcotics anonymous groups, family support groups and individual therapy sessions. The NGO employs social workers, counsellors and community development workers, all of whom assisted in administering the questionnaires across the community.

\section{Research Context}

The community in which the study was located is an under-researched, low-income and poorly resourced rural community located approximately 250 kilometres north of Cape Town, South Africa. The population of the area is comprised of 6120 individuals and Afrikaans is the predominant language spoken (Statistics South Africa 2012). Fishing and agriculture are the main industries and source of employment. However, owing to a decline in these activities, companies employ local community members on a contract rather than a permanent basis (Cederberg Municipality 2015). The selection 
of this area was based on a few reasons. The researchers have a long-standing relationship (approximately eight years) with the community and often conduct outreach programmes for student service-learning. Given this affiliation, as well as the mandate by the Department of Social Development in the White Paper on Families (2013).

The following section continues with a discussion of the data collection procedures. The first phase, the quantitative assessment, required a sample of at least $10 \%$ of the population of the community in order to examine the different family resilience processes present in the sample. After analysis, the second phase of the study required a sample of community stakeholders and other members in order to explore the quantitative results more in depth (Table 1).

\begin{tabular}{|c|c|c|c|}
\hline \multirow{2}{*}{$\begin{array}{l}\text { Table } 1 \text { Demographic } \\
\text { information of } \\
\text { quantitative sample }\end{array}$} & & $n$ & $\%$ \\
\hline & \multicolumn{3}{|l|}{ Gender } \\
\hline & Male & 256 & 39.8 \\
\hline & Female & 388 & 60.2 \\
\hline & \multicolumn{3}{|l|}{ Race } \\
\hline & Coloured & 528 & 82.4 \\
\hline & Black-African & 6 & 0.9 \\
\hline & White & 104 & 16.2 \\
\hline & Mixed race & 3 & 0.5 \\
\hline & \multicolumn{3}{|l|}{ Language } \\
\hline & Afrikaans & 624 & 97 \\
\hline & English & 2 & 0.3 \\
\hline & isiXhosa & 4 & 0.6 \\
\hline & Bilingual & 9 & 1.4 \\
\hline & Multilingual & 4 & 0.6 \\
\hline & \multicolumn{3}{|l|}{ Education } \\
\hline & Primary & 202 & 32.8 \\
\hline & Secondary & 319 & 51.8 \\
\hline & Tertiary & 95 & 15.4 \\
\hline & \multicolumn{3}{|l|}{ Employment } \\
\hline & Employed & 417 & 65.9 \\
\hline & Unemployed & 216 & 34.1 \\
\hline & \multicolumn{3}{|l|}{ Family Position } \\
\hline & Mother & 223 & 34 \\
\hline & Child & 181 & 27.6 \\
\hline & Father & 116 & 17.7 \\
\hline & Aunt & 12 & 1.8 \\
\hline & Grandmother & 8 & 1.2 \\
\hline & Uncle & 6 & 0.9 \\
\hline & Grandfather & 4 & 0.6 \\
\hline
\end{tabular}




\section{Phase 1: Quantitative Assessment \\ Participants}

A convenience sampling method was implemented in the recruitment of participants. The data were collected by means of the door-to-door method with the assistance of fieldworkers. Fieldworkers (who received training on research, ethics and data collection) were requested to approach at least every second house across the entire community. The fieldworkers were volunteers who are associated with the NGO and live within the community. The majority of the participants $(\mathrm{N}=656)$ were female $(\mathrm{n}=60.2 \%)$ and had a mean age of 37.90 years $(\mathrm{SD}=13.92)$ (Table 2). One adult member from each home was selected to participate. Participants were selected based on their availability during the day and willingness to participate when approached. Although $51.8 \%$ of the sample had completed secondary schooling, a large proportion (32.8\%) had not completed any secondary education at all.

The participants' monthly income is summarised in Table 2 and was quite disproportionate. Some participants earned as much as R40 ooo per month whilst many did not receive any income $(\mathrm{M}=3910.35 ; \mathrm{SD}=5506.7)$. This type of financial disparity, although not surprising for a rural community, is still concerning. The disparity between higher income verses the majority lower-income members of such a small community can cause much resentment. This is discussed in more detail.

Table 2 Age \& Income (in Rands)

\begin{tabular}{lcrrr}
\hline & Lowest & Highest & \multicolumn{1}{c}{$M$} & \multicolumn{1}{c}{$S D$} \\
\hline Age & 18 & 80 & 37.90 & 13.92 \\
Monthly income & 0 & 40,000 & 3910.35 & 5506.7 \\
\hline
\end{tabular}

$M$ mean, $S D$ standard deviation

\section{Measures}

The questionnaire administered to participants consisted of a demographic section and the Family Resilience Assessment Scale (FRAS). The FRAS was developed by Sixbey (2005) using Walsh's $(2003,2006,2016)$ theory of family resilience. The FRAS is a 54-item scale designed to measure six dimensions of family resilience: (1) family communication and problem-solving; (2) utilisation of social and economic resources; (3) ability to make meaning of adversity; (4) family connectedness; (5) maintaining a positive outlook, and (6) family spirituality. According to Sixbey (2005), the FRAS total has an internal consistency alpha of 0.96 with these subscales ranging from 0.7-0.96. Plumb (2011) further asserts that the FRAS has demonstrated good concurrent criterion validity with the following scales, namely: the Family Assessment Device 1 (FAD, $\mathrm{r}=0.91)$, FAD $2(\mathrm{r}=0.85)$ as well as the Personal Meaning Index $(r=0.85)$ (Kaya and Arici 2012). 
The FRAS was translated and adapted for use in the research context and was termed the Family Resilience Assessment Scale-Afrikaans Version (FRAS-AV). The adaptation, validation process and outcomes for use in the current study's context are reported elsewhere (see Isaacs, Roman, Savahl \& Sui (2017)).

Consistent with other adaptation and validation studies of the FRAS (Dimech 2014; Kaya and Arici 2012) the overall reliability for the scale, in the current study, demonstrated excellent internal consistency $(\alpha=0.97)$ for use in the kind of community we studied. The sub-scales alphas ranged from 0.38-0.97. However, an analysis of the six subscales showed a low alpha for the subscale for family connectedness $(\alpha=$ 0.38). Four of the items on this six-item scale required reverse scoring. When "nonreversed', the alpha increases to 0.70 . Plumb (2011) states that low reliability can be attributed to the majority of the items of the scale requiring reverse-scoring. Carlson et al. (2012) also found that reverse-scored items might place pressure on respondents cognitively and could lead to less internally consistent items.

\section{Procedures}

Fieldworkers, identified by the local non-governmental organisation (NGO) and trained by the primary author, administered the questionnaire using a convenience sampling method and door-to-door contact across the community $(\mathrm{N}=656)$. The completed questionnaires were securely stored. Once the data were coded, captured and cleaned, they were stored on a password-controlled computer. Data were analysed using the Statistical Package for the Social Sciences v23. The study was exploratory in nature, and therefore descriptive statistics in the form of frequencies and means were computed. Once the quantitative data were analysed and results were confirmed, the qualitative phase was initiated.

\section{Phase 2: Qualitative Assessment Participants}

Four focus group were conducted with community members from distinct participant groups (Ivankova et al. 2006). The selection of the participant groups were made on the guidance and with the assistance of the NGO and represent a non probability convenience sampling method. The majority of these participants had previously completed the FRAS-AV and so could provide valuable input. The staff of the NGO believed that, because of their involvement in the community, they would not only provide valuable input, but also become familiar with and feel more invested in the outcomes of the study. One group comprised five school teachers (T), another group was of 12 religious leaders (RL), a third group comprised 5 staff members of the NGO (RI), and the fourth group was of 5 family members who volunteer at times for the NGO (FM). There were 27 participants in the focus groups, whose mean age was 47.33 years $(\mathrm{SD}=13.04)$. The youngest participant was 22 and the oldest 67 years old.

\section{Data collection and procedures}

The primary author conducted the focus groups with the assistance of a co-facilitator at the NGO, the school and the local municipality building. Discussions were conducted in Afrikaans and lasted about 45 minutes. The co-facilitator transcribed the focus groups verbatim 
and this was reviewed and confirmed by the primary author. The focus group data were analysed using Braun and Clarke's (2006) thematic analysis in Afrikaans. The excerpts were translated into English for the purposes of the present article.

\section{Ethics}

The research study received ethical approval from the research ethics committee of the university (ref. 4/19/14). The researcher also received permission from the developer of the FRAS in order to conduct use the instrument. Informed consent was explained and obtained at several stages from the parties involved: the NGO, fieldworkers before their training, and participants in both the quantitative and qualitative phases. The issue of confidentiality was especially important to ensure as the NGO was involved in most of the participant recruitments. Therefore, no potential participant would be discriminated against should they have chosen to not participate or remove themselves from the research process. Further, the NGO was the point of referral for any participant or fieldworker who felt that they were in need of further assistance. For example, if any participant felt discomfort as a result of the questionnaire, the fieldworkers would refer them for the appropriate service.

\section{Results}

The results are presented in accordance with the phases of the research design. In other words, the results are presented as the data was collected and analysed: Firstly, the quantitative results are shown (phase 1) and then the qualitative results are described (phase 2) and secondly; a discussion follows with a combined narrative of both the quantitative and qualitative results.

\section{Phase 1: Quantitative Results \\ Table summary}

Table 3 presents an analysis of the adversities that the participant sample had experienced in the previous five years. Table 4 is a means analysis of family resilience dimensions. Tables 5 , $6,7,8,9$, and 10 comprise further means analysis of each of the family resilience dimension's items.

Table 3 identifies a range of crises families experienced within the previous five years. It would appear that the death of a loved one $(n=148)$ was the most prominent adverse experience within this sample. However, if one views unemployment and financial uncertainty as similar thematic concepts, it seems that economic instability was the most common crisis experienced. Some participants indicated that they would be unemployed within a month of completing the questionnaire. Given the scarcity of employment opportunities, it would be reasonable to view them as practically similar.

The means analysis in Table 4 shows the scores of the family resilience dimensions. Family connectedness has the lowest scoring mean $(\mathrm{M}=2.64$; $\mathrm{SD}=0.43)$, followed by utilising social and economic resources $(\mathrm{M}=2.85 ; \mathrm{SD}=0.66)$. Although the convention is to round up figures, these data do not depict a very high level of resilience. Tables 5, 6, 7, 8, 9, and 10 illustrate the mean breakdown for all six dimensions, with items closer to 4 
indicating a higher level of resilience.

Table 3 Adversities experienced in the previous 5 years

\begin{tabular}{lrr}
\hline Type of adversity & \multicolumn{1}{c}{$n$} & $\%$ \\
\hline Death of alloved one & 148 & 43.7 \\
Unemployment & 81 & 23.9 \\
Financial uncertainty & 75 & 22.1 \\
Illness of a loved one & 29 & 8.6 \\
Divorce & 4 & 1.2 \\
Other & 1 & 0.3 \\
\hline
\end{tabular}

Participants were mostly in agreement with the item dimensions of family communication and problem solving. In no instance did participants mostly disagree with any of the items, indicating an 'agreeable' level of being able to solve problems and communicate effectively. However, the two items with the closest ratio of Disagree to Agree were 'We are understood by family members.' and 'We can blow off steam at home without upsetting someone.' We can surmise that not all family members would feel comfortable being able to express their daily frustrations in the family.

Utilising social and economic resources encompasses a range of item dimensions. It refers to the relationships among friends, neighbours and the community at large. The sample was almost split in their perceptions regarding the dimensions of social and economic resources. The lower-scoring mean items were 'We receive gifts and favours from neighbours.' and 'We ask neighbours for help and assistance.' Perspectives on neighbours and other community members is further explored and explained on in the qualitative results and discussion.

A possible strength of the community appears to be its ability to maintain a reasonably positive outlook. Very few participants believed that they were not able to see their problems through. Maintaining a positive outlook is also a function of their higher belief systems.

Table 8 further informs the understanding of the mean score presented in Table 4. There is not much agreement regarding being 'too involved' with others in their community. An item frequency analysis (Table 9, below) shows that there is almost a 50/50 split between those who (strongly) agree and (strongly) disagree with feeling taken for granted, keeping their feelings to themselves, listening to the concerns of others, and not getting too involved with those in the community. However, participants did believe that they shared love and affection for those in their family. 
Table 4 Family resilience means analysis per dimension

\begin{tabular}{lll}
\hline Dimension & $M$ & $S D$ \\
\hline Family communication and problem solving & 3.22 & 0.49 \\
Utilising social and economic resources & 2.85 & 0.66 \\
Maintaining a positive outlook & 3.22 & 0.50 \\
Family connectedness & 2.64 & 0.43 \\
Family spirituality & 3.40 & 0.59 \\
Ability to make meaning of adversity & 3.39 & 0.50 \\
Family resilience (overall mean) & 3.14 & 0.41 \\
\hline
\end{tabular}

Table 5 Family communication and problem solving

\begin{tabular}{llll}
\hline Family communication and problem solving & $n$ & $M$ & $S D$ \\
\hline Our family structure is flexible to deal with the unexpected. & 648 & 3.25 & 0.654 \\
We all have input into major family decisions. & 653 & 3.17 & 0.726 \\
We are able to work through pain and come to an understanding. & 650 & 3.25 & 0.623 \\
We are adaptable to demands placed on us as a family. & 652 & 3.23 & 0.665 \\
We are open to new ways of doing things. & 650 & 3.22 & 0.67 \\
We are understood by other family members. & 649 & 3.02 & 0.799 \\
We can ask for clarification if we do not understand each other. & 652 & 3.18 & 0.711 \\
We can be honest and direct with each other in our family. & 649 & 3.23 & 0.724 \\
We can blow off steam at home without upsetting someone. & 641 & 2.96 & 0.835 \\
We can compromise when problems come up. & 653 & 3.16 & 0.691 \\
We can deal with family differences in accepting a loss. & 649 & 3.24 & 0.624 \\
We can question the meaning behind messages in our family. & 652 & 3.1 & 0.71 \\
We can talk about the way we communicate in our family. & 651 & 3.24 & 0.688 \\
We can work through difficulties as a family. & 655 & 3.28 & 0.609 \\
We consult with each other about decisions. & 655 & 3.18 & 0.728 \\
We define problems positively to solve them. & 654 & 3.25 & 0.632 \\
We discuss problems and feel good about the solutions. & 655 & 3.16 & 0.697 \\
We discuss things until we reach a resolution. & 652 & 3.11 & 0.71 \\
We feel free to express our opinions. & 648 & 3.19 & 0.684 \\
We feel good giving time and energy to our family. & 652 & 3.35 & 0.614 \\
We leam from each other's mistakes. & 648 & 3.33 & 0.617 \\
We mean what we say to each other in our family. & 652 & 3.15 & 0.754 \\
We share responsibility in the family. & 651 & 3.2 & 0.7 \\
We tell each other how much we care for one another. & 652 & 3.25 & 0.697 \\
We try new ways of working with problems. & 652 & 3.28 & 0.641 \\
We understand communication from other family members. & 652 & 3.2 & 0.683 \\
We work to make sure family members are not emotionally or physically hurt. & 649 & 3.4 & 0.635 \\
\hline & & & \\
\hline
\end{tabular}

Family spirituality and the ability to make meaning of adversity (Table 10) have the highest scoring items. These community members appear to be able to find meaning in challenges or crises. There is a common belief that there exists a supreme being and participants further accept to some degree that problems occur unexpectedly. These descriptions were explored in more depth in the focus groups. 


\section{Phase 2: Qualitative Results}

This study adopted a mixed methods design. As such, the first point of method 'mixing' is the stage at which the results of the quantitative analysis become the basis for the formulation of the research questions in the qualitative phase, and is known as the intermediate stage (Ivankova et al. 2006).

Table 6 Utilising social and economic resources

\begin{tabular}{llll}
\hline Utilising social and economic resources & $n$ & $M$ & $S D$ \\
\hline We ask neighbours for help and assistance. & 649 & 2.8 & 0.917 \\
We can depend upon people in this community. & 653 & 2.87 & 0.889 \\
We feel people in this community are willing to help in an emergency. & 649 & 2.86 & 0.912 \\
We feel secure living in this community. & 643 & 2.83 & 0.971 \\
We know there is community help if there is trouble. & 648 & 2.89 & 0.878 \\
We know we are important to our friends. & 652 & 3.17 & 0.746 \\
We receive gifts and favours from neighbours. & 650 & 2.68 & 0.936 \\
We think this is a good community to raise children. & 651 & 2.81 & 1.002 \\
\hline
\end{tabular}

Table 7 Maintaining a positive outlook

\begin{tabular}{llll}
\hline Maintaining a positive outlook & $n$ & $M$ & $S D$ \\
\hline We believe we can handle our problems. & 646 & 3.26 & 0.601 \\
We can solve major problems. & 651 & 3.12 & 0.753 \\
We can survive if another problem comes up. & 653 & 3.25 & 0.581 \\
We feel we are strong in facing big problems. & 649 & 3.1 & 0.756 \\
We have the strength to solve our problems. & 646 & 3.24 & 0.643 \\
We trust things will work out even in difficult times. & 645 & 3.36 & 0.581 \\
\hline
\end{tabular}

Ungar (2010) notes that the (mixed) method of both honouring differences and identifying commonalities works best when allowance is made for an analysis of the relative discursive power of those who decide what words such as 'family resilience' and 'well-being' could mean to different populations. The current section explores those meanings for such community members.

The semi-structured focus group discussion guide was constructed in order to gauge a deeper understanding of the concepts of the quantitative results (such as the low scores for utilising social and economic resources, family connectedness and high scores for family spirituality) as well as illuminate them with contextualised experiences. The focus groups were structured in the following way. First, participants were asked to provide their experience of completing the questionnaire; second, after a brief presentation of the results, they were asked to reflect on the results and provide their opinions and insights (based on their experience in the community); finally, they were also asked to reflect on their own family life and the larger community. The results were presented to the focus groups, as it is above, with a more simplistic explanation of the tables. We provided an opportunity for participants to understand the quantitative results so that they could provide their insights from an informed perspective. Three major thematic categories were identified from the focus groups: community 
and family challenges; community belief systems; and current family functioning and organisational patterns.

\section{Community and Family Challenges}

There was a belief that family life, as well as the ability to provide for the family and function optimally, had become more challenging. They were referring to the perception that looking back to when they were younger, family life seemed less complex and more stable. Participants specifically referred to fears about safety for themselves and, more importantly, their children. Further problems identified in the community as hindrances to family life were substance use, crime and a general distrust of others. This theme especially illuminates the nuances of what problems these families can be experiencing (as indicated in the results above), as well as contextual factors which can compound them. These issues are indicated in the excerpts below (the relevant participant's group affiliation ${ }^{1}$ follow in parentheses):

The questionnaire showed me that [the community] is not a safe place to raise children. I looked around because crystal meth is taking over [the community], and in today's time, I can't send my child to the shop with a $\mathrm{R}^{2} \mathrm{O}^{2}$ and expect them to come home. (FM) I've also recently been a victim of crime... when my eldest daughter and my son's shoes were drying on the washing line. So they've stolen two pairs of shoes and they were not cheap. (FM)

The participants were open in terms of their experience of completing the questionnaire as well as how it started to make them think about their community and fellow neighbours. Participants also discussed the degree of trust, or lack thereof, between neighbours and the larger community which could explain the low scoring of Utilising social and economic resources and Family connectedness on the quantitative scales. One of the factors (among substance use and crime concerns) contributing to distrust was thought to be jealousy.

What I've also realised in this community is that people do not trust each other. I almost get the feeling that one person does not want the other to succeed. They don't want anyone else to have anything. (RI) We call it the crayfish mentality... when you catch crayfish in a net, they usually try to get out. Usually the crayfish at the bottom pull the crayfish at the top down. Instead of helping each other, they keep each other in the net. (RI)

More than jealousy, this 'crayfish mentality' or loss of community connectedness, can also be attributed to larger structural issues such as the lack of employment opportunities, and the unavailability of resources.

\section{Lack of Resources}

One of the findings among the quantitative results was a perception of a low sense of social and economic resources; this was also expressed as some examples of the challenges experienced

\footnotetext{
${ }^{1}$ FM: family members; RI: NGO; RL: Religious leaders

${ }^{2}$ R20: the currency in South Africa is measured in Rands. This will afford you a loaf of bread.
} 
by families in this community in the focus group discussions:

Table 8 Family connectedness

\begin{tabular}{llll}
\hline Family connectedness & $n$ & $M$ & $S D$ \\
\hline Our friends value us and who we are. & 649 & 3.2 & 0.725 \\
We show love and affection for family members. & 651 & 3.33 & 0.67 \\
We feel taken for granted by family members.* & 650 & 2.65 & 0.942 \\
We keep our feelings to ourselves.* & 652 & 2.74 & 0.886 \\
We seldom listen to family members' concerns or problems.* & 650 & 2.73 & 0.892 \\
We think we should not get too involved with people in this community.* & 648 & 2.57 & 0.89 \\
\hline
\end{tabular}

*Indicates negatively phrased items

We have a problem with low-income housing ... everyone lives in one room ... so many of our children come to school hungry ... a lot of them are in the feeding scheme and it is the only way they are able to eat. (T) The children need counselling, here is too little. One person is too few. Here are too many children that need counselling. At the end of the day, you refer a lot of children and only two can be seen to, for example ... the others cannot be seen. That child once again feels as though someone has disappointed them ... 'I want to talk' and now suddenly the person isn't there. (T) There is no economy, no economy, here are no employment opportunities ... here is nothing going on ... what are our children going to do? (RL)

According to these participants, these are adversities experienced almost daily and are compounded by the lack of resources available and poor infrastructure to support or overcome these adversities.

\section{Parenting}

Participants also discussed other challenges they experience in the community, especially in terms of poor communication and parenting. All participants described various problems that they believed children experience at home, such as there being little communication and strained relationships with their parents, as the reason why children are aggressive, lie and steal at school.

Inside our homes, I believe that the majority of our parents do not know how to communicate with their children in the right way. We experience the aggression that is displayed at home, we experience it here at school. (T) One can pick up very quickly how parents communicate with their children at home... Our children do not know how to talk, and to talk to their mothers like that is normal - because that's what is happening at home - they grow up like that. (T)

Participants believed that good and effective forms of communication would improve family life; however, they also shared their perceptions that this is not practiced at home, which was problematic for them as there was a widespread belief that such things 'start at home'. This was also discussed in reference to the quantitative finding of 'family communication and problem solving'. 
I voluntarily work with the children - share with the children. I ask them about their relationship with their mother at home. Many of our children say they do not have a relationship...people don't always want to be talked to by this group - by outsiders - then they say you are interfering... 'Leave us alone, we will sort out our own problems.' (RL)

Table 9 Family connectedness: frequencies

\begin{tabular}{lllll}
\hline & $\begin{array}{l}\text { Strongly } \\
\text { agree }\end{array}$ & Agree & Disagree & $\begin{array}{c}\text { Strongly } \\
\text { Disagree }\end{array}$ \\
\hline Our friends value us and who we are. & 244 & 297 & 103 & 5 \\
We show love and affection for family members. & 274 & 331 & 32 & 14 \\
We feel taken for granted by family members.* & 140 & 216 & 220 & 74 \\
We keep our feelings to ourselves.* & 142 & 246 & 214 & 50 \\
$\begin{array}{l}\text { We seldom listen to family members' concerns or } \\
\text { problems.* }\end{array}$ & 144 & 237 & 219 & 50 \\
$\begin{array}{l}\text { We think we should not get too involved with people in } \\
\text { this community.* }\end{array}$ & 117 & 194 & 277 & 60 \\
\hline
\end{tabular}

*Indicates reversed item scoring

\begin{tabular}{llll}
\hline Family spirituality & $n$ & $M$ & $S D$ \\
\hline We attend church/synagogue/mosque services. & 649 & 3.43 & 0.717 \\
We have faith in a supreme being. & 643 & 3.58 & 0.573 \\
We participate in church activities. & 654 & 3.3 & 0.788 \\
We seek advice from religious advisors. & 653 & 3.27 & 0.839 \\
Ability to make meaning of adversity & & & \\
The things we do for each other make us feel part of the family. & 652 & 3.35 & 0.637 \\
We accept stressful events as a part of life. & 653 & 3.35 & 0.674 \\
We accept that problems occur unexpectedly. & 652 & 3.45 & 0.539 \\
\hline
\end{tabular}

There is a small boy who lives on my street. I asked him why he's not at crèche. Yesterday morning, he came to me and I don't know...he's only four years old. He is, at this very moment, walking around. Mother is at work. The sister is at home. They're not at school anymore because exams are finished. But during the day, half of the day he's alone. Grandmother is there but not always mentally present. (FM)

The excerpt above refers to grandparents and the role they play in this community. Skipgeneration households are common in this community. Although the number of skipgeneration households are increasing (Das \& Zimmer, 2015), grandparents are not always successful in meeting the needs of children as primary caregivers (Shin et al. 2010); this could be the result of advanced age, illness and/or not having the financial means to support their families if they are retired. Additionally, urban households tend to be better able to meet family financial needs than those skip-generation households in rural areas (Das \& Zimmer, 2015).

\section{Perspectives on Current Family Organisational Patterns}

Walsh (2012) asserts that the family's reactions to challenges enable the family unit either to rally or to fall apart. Engaging in processes, which can strengthen the family during such times, is vital to increasing family resilience. Perspectives on how families 
currently connect or disconnect from each other and the community are explained in this theme. This is aligned to those findings in the quantitative results, particularly utilising social and economic resources and the larger theoretical dimension of family organisation patterns (Walsh 2016). These strategies range from recognising the position of differing family roles, having monthly family meetings (which improve communication) and a strong belief in a higher spiritual power. Some participants identified themselves as the 'fixer' - the family fixer, the individual who takes the leadership role in a situation.

By us, mummy sorts everything out. Mummy makes everything right. We sit behind and watch. (RI) I can only speak of my own context. I was groomed to be the fixer for years and when I got married my brother took on the responsibility. It didn't last very long and then I was drawn in again. I don't know what will happen if there is no fixer. If I didn't live so close or I wasn't in town perhaps then hewould've stepped up as fixer. I think it's just how we are made - there has to be one in the family, one who acts as the fixer and takes the lead and gives guidance on how the situation should be handled. (RI)

Based on the descriptions in the above excerpts, participants seemed intuitively aware of each member's role within the family unit, especially recognising the various personalities/roles in a crisis. Theoretically, this recognition is an important component of the family's organisational patterns. Participants referred to a position of 'fixer' both within and outside the home.

There needs to be a 'cool head'. Everyone going through the crisis will go through a phase of shock but there must be someone who is 'cool' in the crisis. And when you get home, you take it out on your wife. But you need that one or two people who, in any given situation, acts as the fixer or leader. And it places a terrible amount of stress on that person and his home family. (RI)

However, awareness of these roles, rules and rituals alone is not enough. Having astute organisational patterns alone is not enough to be able to weather adversity.

With us, it depends on what or who the problem is. But we will all sit and talk but it will depend on what the crisis is.^ (RI) Each month we have a family meeting in planning for the month. How can we make it better? How can we change it? (FM)

It is evident that some families are able to create effective organisational patterns using communication as a tool. Their meetings encourage open and honest communication among family members.

\section{Community Belief Systems}

Within the quantitative results, there was an indication that families' belief systems within the community were strong. There was a strong belief in a 'higher power', participation in religious rituals and modelling behaviour based on predominantly Christian teachings within 
the church. These spiritual beliefs form part of families' daily functioning and possibly help to make meaning of their adversities and maintain a positive outlook, as indicated below:

I'm thinking now... at one stage in my family, about two years ago... I got to the point that... it was after my mother's death. Then things came out and there were things said to me. My mother stayed by me. She had cancer. And so I started hearing that I never looked after her well enough. So I decided, after my mother's funeral, they can go. I don't need them. That's how I felt - my fiancé and two children are my family now. I cut myself off from everyone. I didn't have a mother. I didn't have a father. I had sisters and uncles and aunties and that. I decided, 'Look at how they treated you - they are not part of me'. I have now a 'home family' and the people around me. So we were and that was my family. And then my sister starting calling. I thought, 'Why are you calling?' and then one day I thought, 'Oh well, [expletive] man! They are family and we need each other. We are sisters and if there is an emergency or if there's death, what happens then?' And I thought then I'd make a change. I started thinking that was right. I was guilty as well. I mean, whether I asked for forgiveness or what. I thought, "No man, that is my blessing.' The Lord was hurt even more than I was. And the Lord forgave. And I forgave them. They are family. (FM)

Although there was confirmation that belief systems would score higher than any other family resilience dimension, many participants believe that the picture was incomplete. For example, if one considers some of the concerns raised above under perceptions of community and family challenges, it would be incorrect to assume that religious beliefs are automatically transferred within families under all circumstances. Some participants took the view that religious and spiritual beliefs were far too exalted and at times used as a crutch, while others made an argument for the lack of other vital processes such as communication, facing and dealing with their emotions, as well as good role models.

Like in my substance abuse field, the church people will say that they don't believe in a rehab programme. You have to be converted... and then you really sit with a problem. (RI)

You expect people to be angry but then they'll say, 'No, it is God's will'. It makes one a bit disheartened, you know? (RI)

I mean, if you just listen to what's been said about communication and emotions openly express and problem solving and consistent messages... in my opinion, I'd say that before you even consider the organisational patterns, the communication should be addressed well... the focus cannot be on organisational alone. (RI)

Participants were also expressive in terms of their beliefs of good family functioning. They identified communication as being at the heart of some of the family organisational problems experienced. Participants were of the opinion that the concept of communication should also be a considered 'need' of families in the community. 


\section{Discussion}

As Walsh (2006) has explained, 'The major problems of families today largely reflect difficulties in adaptation to the social and economic upheavals of recent decades and the unresponsiveness of larger community and social institutions.' (p. 102). Both the quantitative and qualitative results in the present study highlighted economic instability as one of the most common adversities experienced by families. The socioeconomic environment within the community and the larger country is not conducive to creating sustainable employment opportunities. The community is characterised by high levels of substance use, low education levels and high unemployment rates. Increases in crime have been attributed to high substance use and unemployment rates (Western Cape Safety Report 2013). Seccombe (2002) and Holborn and Eddy (2011) refer to the term 'economic hardship' as being a debilitating contextual factor in the lives of families. Participants discussed their perspectives on the effects of there not being a growing economy and viable opportunities for young people to obtain employment.

As indicated in the findings, participants believed that social and economic resources were challenging to mobilise, and several reasons were given for this finding. In terms of the quantitative findings, the concept of 'utilising social and economic resources' predominantly focuses on participants' perceptions of their community, and their feelings of safety and security and being able to depend upon neighbours for help. When people contribute within the community, they tend to feel secure and can rely in turn on existing social networks when they need them (Walsh 2006). During interviews, participants attributed poor social networks within the community to jealousy; a phenomenon they termed the crayfish mentality. This comment is generally regarded as disparaging and offensive. The community in question is known as a fishing community and, as such, the term is apt. This community jealousy can result in less people sharing their achievements. In turn, people did not necessarily feel sufficiently safe and secure to ask for assistance when they needed it, thus hindering their mobilisation of social and economic resources.

The concepts of safety and security were also discussed within the crime and substance abuse problems that this community experiences (Philip et al. 2014). Participants disclosed that opportunities to seek long-term assistance were very limited. Sustainable social resources need to be established, therefore. Walsh (2006) observes that research has repeatedly found that the leading concern of parents is the challenge of balancing work, family life and quality childcare. This finding is also consistent with those of Coley and Lombardi (2014) who also describe the strains on their roles that families experience in maintaining optimal environments for their members.

A need for family connectedness was found in both the quantitative and qualitative results. The questionnaire showed low-scoring items (such as 'We feel taken for granted by family members.' and 'We think we should not get too involved with peopl e in this community.'). The concept of family resilience also presupposes a relational dimension because it involves mutual support, teamwork, respect (of individual needs and differences) and an ability to reconnect or restore broken relationships 
(Walsh 2016). For example, in the study by Vermeulen and Greeff (2015), the authors report experiencing families as having a deep connection within their surrounding environment. Moreover, they community-related factors also greatly affected the families' level of resilience.

Within this study, participants shared how perceived problems are addressed in their homes and communities. When a fight or disagreement emerges, family members tend to stop speaking with one another until after they have calmed down, and only then can communicate again. It is within such an example that having leadership in the family is important.

Participants further believed that the 'fixer' (perhaps a parent or other caregiver) played an integral role in the lives of their families. For example, family members who take on leadership roles and set firm boundaries within the home are also more likely to take on leadership or advocacy roles outside the home (Reynolds et al. 2015). Establishing and reinforcing family boundaries and roles (Walsh 2006), typically set by a parent or caregiver, is also essential in maintaining connectedness as it further enhances parental authority and family relationships (Mayberry et al. 2014). It would be important to focus on this aspect in a family resilience programme. Similarly, Masten (2015) also emphasises the significance of family routines/rituals in interventions aimed at strengthening family resilience.

The quantitative and qualitative findings revealed that the participants belong to a very spiritual community, which has a strong belief in prayer, faith and a 'higher power'. Family spirituality revealed the highest mean scores among all other family resilience dimensions on the FRAS. There has been much research devoted to organisational religiosity, which includes the various denominations and public practices such as participation in services and other religious engagements (Greeff and Loubser 2008; Koerner et al. 2013). Black et al. (2014) posit that meaning making is an important part of family bonding as well as being an integral part of a family's belief systems (Walsh 2012). Walsh (2016) extends the understanding of the concept of belief systems as encompassing more than religion and spirituality; it also includes worldviews, attitudes and perceptions of individual family members and the level to which these are similar or dissimilar to those of individual family units (Brelsford and Mahoney 2008). The community under review practises the Christian religion predominantly, which was evident in the various discussions. During the NGO meetings, however, participants also shared their concerns when referring to community members' spiritual beliefs, as they believed that at times their beliefs deterred them from seeking professional or other community help (Koerner et al. 2013). They were concerned that over-reliance on one coping strategy (such as the belief that a higher power will resolve all problems) could constrain them from seeking needed and available assistance.

Participants described the poor quality of relationships and lack of communication as pervasive problems in the community. The focus group discussions highlighted the belief that communication was an integral function of the family. This is also in accordance with other South African family resilience literature such as der Kinderen and Greeff (2003), who found 
communication to be an important positive influence in improving the interdependent family system. Bandura et al. (2011) and Banovcinova and Levicka (2015) confirm that effective communication is essential to the functioning of the family. Liermann and Norton (2016) suggest that improved communication may have greater results in encouraging empathy and understanding from other family members.

The result of the mixed methodological sequential design was particularly useful for the present study. Research has not been conducted in the past on such a large scale in this community, and it was the first time that many community members had an opportunity to reflect and provide input on their perceptions of family life as well as how this information can be used to develop an effective family-based intervention. It was evident in the qualitative group discussions that participants were enthusiastic and encouraged not only by the results of the quantitative phase, but also by the opportunity to provide input and facilitate open discussions on how to begin addressing the issues raised with the various organisations in the community. One of the ways in which these issues would be addressed would be in the form of an intervention designed to strengthen families, based on the needs identified through the research process and continuous input from the community. Based on the findings of the study, the identified family resilience needs were that of family connectedness and the presence and use of social and economic resources. Through the qualitative phase, communication within the family was also suggested as an important need in the community and should be a consideration for the intervention.

Although the present study did not aim to locate itself within a transformative paradigm, the findings from the qualitative discussions, however, appear to support an argument for transformative mixed methods. Mertens (2007) posits that although there is no typical set of instructions to conduct research within the transformative paradigm, there are dimensions, which may be present, suggesting a transformative approach; such as the initial and continuous consultation with community members. Similarly, the current study values the co-creation of knowledge with community input, and thus the aims and objectives of the larger study (and even data collection methods) are decided upon in continuous dialogue with the NGO. It was encouraging for the researchers to witness and be involved in negotiations around the creation of better working relationships between all stakeholders to be catalysts in the transformation and empowerment of their community and its families.

\section{Limitations \& Recommendations}

The sampling method utilised was a non-probability convenience method for both quantitative and qualitative components of the study. Although the community is small and the fieldworkers had collected information from across the entire community, the results cannot be stated as a representative sample. Future studies could seek to not only investigate these family resilience concepts from a generalizable sample, but also to approach more than one member of the same family. The findings of this study will be used in the process to develop a family resilience strengthening intervention. Through this research approach, we have identified possible intervention objectives and have been able to secure community buy-in in the development and refinement of the intervention. 


\section{Conclusion}

The present study highlighted the dimensions of family resilience in which families from the reviewed community might struggle. Further, this study also provides depth to the emerging field of family resilience.

First, family connectedness and utilisation of social and economic resources were found to be low-scoring on the quantitative measure. According to Walsh (2016), both family connectedness and utilising social and economic resources are related to the family organisational patterns domain of family resilience. However, participants believed that organisational patterns within the family were not the only challenge within families. Some participants gave accounts of their own experiences where they believed that communication would also need to be addressed in the programme as it is the basis for any resilience fostering.

Second, the highest level of mean scores was found on the family spirituality dimension and was further elaborated on during focus group discussions. Participants spoke of their beliefs and having faith as their hope for change, as well as how their religion is used as a model for their families by which to live. Arguably, these higher belief systems could be an explanation for possibly rigid and assumptive views on family life. For example, a family should not 'reach out' in times of crisis, but should rather believe that all would resolve itself with enough faith. According to Koerner et al. (2013), incorporating religious views is critical when developing contextually sensitive programmes, especially when it is used as a coping strategy for a particular population.

Third, the findings have implications not only for advancing our understanding of family resilience and its processes but also on how to view family resilience assessments and the effects on the sample. For example, although the focus group discussions involved small numbers of participants, they led to increased reflection, motivation and communication not only between the study's participants but also between different and important systems in the community: the church, the school and the NGO. Therefore, there was evidence that the study's mixed method design could locate itself to the transformative paradigm. The primary author's relationship with the community will continue with the introduction of other methods in order to develop a contextual, culturally sensitive programme for improving family resilience levels. Mertens (2007) suggests a cyclical model of mixed methods as a means of continuing the involvement of the community, enhancing trust and using the results to further the goal of transformation. This approach is also aligned with the goal of using a family resilience approach, of transformation and fostering empowerment.

Finally, all the results should be framed within the context of socioeconomic instability. According to Seccombe (2002) and Walsh (2012), it is not enough to do research only, but also to apply social policy so as to not only beat the odds but also to change the odds. For example, the White Paper on South African Families (2013) has its vision in developing healthy families and increasing family resilience. However, having anofficial document does not necessarily translate into immediate effects for families. Moreover, although the country's Millennium 
Development Goals speaks to the eradication of poverty, there is no anti-poverty strategy in place (Madonsela 2017). If it is accepted that the difficult social and economic conditions described are contributory to destabilising family wellbeing, and if it is wished to promote healthy family wellbeing, it is necessary to provide an environment within which families are able to access resources that will help them to perform their basic functions. It may not be possible to immediately change the environment; however, it may be possible to create a holding environment that enables families to begin changing their own odds.

Compliance with Ethical Standards All procedures performed in studies involving human participants were in accordance with the ethical standards of the institutional and/or national research committee and with the 1964 Helsinki declaration and its later amendments or comparable ethical standards. Serena Isaacs, as a PhD student, has received a research grant from the National Research Foundation of South Africa (Thuthuka grant number: 93975). Professors Nicolette Roman and Shazly Savahl have not received any funding and declare no conflicts of interest.

Informed Consent Informed consent was obtained from all individual participants included in the study. 


\section{References}

Ahmed, Z. S. (2005). Poverty, family stress and parenting. Retrieved from http://www .humiliationstudies.org/d ocume n ts / AhmedPovertyFamilyStressParenting.pdf. Accessed 18 May 2015. Bandura, A., Caprara, G. V., Barbaranelli, C., Regalia, C., \& Scabini, E. (2011). Impact of family efficacy beliefs on quality of family functioning and satisfaction with family life. Applied Psychology: An International Review, 6o(3), 421448.

Banovcinova, A., \& Levicka, K. (2015). The impact of the financial income on the family communication. Revista Romaneasca pentru Educatie Multidimensionala, 7(2), 35-46. https://doi.org/10.18662/ rrem/2015.0702.03.

Banovcinova, A., Levicka, J., \& Veres, M. (2014). The impact of poverty on the family system functioning. Procedia - Social and Behavioral Sciences, 132, 148-153.

Black, K., \& Lobo, M. (2008). A conceptual review of family resilience factors. Journal of Family Nursing, 14(1), 33-55. https://doi.org/10.1177/107484070731223.

Black, H. K., Santonello, H. R., \& Rubenstein, R. L. (2014). A pragmatic belief system in family meaning-making after death. Death Studies, 38, 522-530. https://doi.org/10.1080/07481187.2013.879754.

Blair, C., \& Raver, C. C. (2012). Child development in the context of adversity: Experiential canalization of brain and behaviour. American Psychologist, 67(4), 309-318. https://doi.org/10.1037/ aoo27493.

Braun, V., \& Clarke, V. (2006). Using thematic analysis in psychology. Qualitative Research in Psychology, 3(2), 77-101. https://doi.org/10.1191/1478088706qpo63oa.

Brelsford, G. M., \& Mahoney, A. (2008). Spiritual disclosure between older adolescents and their mothers. Journal of Family Psychology, 22(1), 62-70. https://doi.org/10.1037/0893-3200.22.1.62.

Carlson, M., Wilcox, R., Chou, C., Chang, M., Yang, F., Blanchard, J., et al. (2012). Psychometric properties of reverse-scored items on the CES-D in a sample of ethnically diverse older adults. Psychological Assessment, 23(2), 558-562.

Casale, M., Lane, T., Sello, L., Kuo, C., \& Cluver, L. (2013). Conducting health survey research in a deep rural South African community: Challenges and adaptive strategies. Health Research Policy \& Systems, 11(1), 1-11.

Cederberg Municipality (2015). Annual report 2014/2015. Retrieved from http://www. cederbergmun.gov.za/sites/default/files/documents/20142015\%20Annual\%20Report.pdf. Accessed 6 June 2016.

Coley, R. L., \& Lombardi, C. M. (2014). Low-income women's employ- ment experiences and their financial, personal, and family well-being. Journal of Family Psychology, 28(1), 88-97. https://doi.org/10.1037/a0034998.

Cornish-Jenkins, H. (2016, February). Despite the 1994 political victory against apartheid, its economic legacy persists. http://www.sahistory.org.za/article/despite-1994political-victory-against-apartheid-its-economic-legacy-persists-haydn-cornish-. Accessed 27 Sept 2017.

Das, S., \& Zimmer, Z. (2015). Living arrangements and wealth among skip generation households across the globe. International Journal of Sociology of the Family, 41(2), 95-116. 
DeHaan, L. G., Hawley, D. R., \& Deal, J. E. (2015). Operationalizing family resilience as process: Proposed methodological strategies. In D. S. Becvar (Ed.), Handbook of Family Resilience. New York: Springer.

Dimech, S. (2014). Validating the Family Resilience Assessment Scale to Maltese families. Unpublished masters dissertation. University of Malta: Malta.

Greeff, A. P., \& Loubser, K. (2008). Spirituality as a resiliency quality in Xhosa-speaking families in South Africa. Journal of Religion and Health, 47, 288-301. https://doi.org/10.1007/s10943-007-9157-7.

Holborn, L., \& Eddy, G. (2011). First steps to healing the South African family. Johannesburg: South African Institute of Race Relations.

Isaacs, S., Roman, N.V., Savahl, S. \& Sui, X.C. (2017). Adapting and validating the family resilience assessment scale for use in an Afrikaans rural community in South Africa. Community Mental Health Journal. https://doi.org/10.1007/s10597-017-0091-1.

Ivankova, N. V., Creswell, J. W., \& Stick, S. L. (2006). Using mixed- methods sequential explanatory design: From theory to practice. Field Methods, 18 (3), 3-20. http s://doi.org/10.1177/1525822X05282260.

Jonker, L., \& Greeff, A. P. (2009). Resilience factors in families living with people with mental illness. Journal of Community Psychology, 37(7), 859-873.

Kaya, M., \& Arici, N. (2012). Turkish version of shortened family resilience scale: the study of validity and reliability. Procedia - Social and Behavioral Sciences, 55, 512-520.

Keswell, M. (2005). Education and racial inequality in post apartheid South Africa. Retrieved from www.ekon.sun.ac.za/mkeswell/ education_and_racewd.pdf. Accessed 18 May 2015.

der Kinderen, S., \& Greeff, A. P. (2003). Resilience among families where a parent has accepted a voluntary teacher's retrenchment package. South African Journal of Psychology, 33(2), 86-94. https://doi.org/10.1177/008124630303300203.

Koerner, S. S., Shirai, Y., \& Pedroza, R. (2013). Role of religious/spiritual beliefs and practices among Latino family caregivers of Mexican descent. Journal of Latina/o Psychology, 1(2), 95-111. https://doi. org/10.1037/aoo32438.

Liermann, K., \& Norton, C. L. (2016). Enhancing family communication: Examining the impact of a therapeutic wilderness program for struggling teens and parents. Contemporary Family Therapy, 38, 14-22. https://doi.org/10.1007/s10591-015-9371-5.

Lietz, C. A. (2013). Family resilience in the context of high-risk situations. In D. S. Becvar (Ed.), Handbook of family resilience. New York: Springer.

Madonsela, T. (2017, August). Children must be a priority. http://www. news24.com/Columnists/GuestColumn/children-must-be-a-priority-20170825. Accessed 27 Sept 2017.

Mayberry, L. S., Shinn, M., Benton, J. G., \& Wise, J. (2014). Families experiencing housing instability: The effects of housing programs on family routines and rituals. American Journal of Orthopsychiatry, 84(1), 95-109. https://doi.org/10.1037/hoo98946. Mertens, D. M. (2007). Transformative paradigm: Mixed methods and social justice. Journal of Mixed Methods Research, 1(3), 212-225. https://doi.org/10.1177/1558689807302811.

Miglorini, L., Rania, D., Tassara, T., \& Cardinali, P. (2016). Family routine behaviors and 
meaningful rituals: A comparison between Italian and migrant couples. Social Behavior and Personality, 44(1), 9-18. https://doi.org/10.2224/sbp.2016.44.1.9.

Morris, L. D., Grimmer-Somers, K. A., Louw, Q. A., \& Sullivan, M. J. (2012). Cross-cultural adaptation and validation of the South African Pain Catastrophizing Scale (SA-PCS) among patients with fibromyalgia. Health and Quality Life Outcomes, 10, 137 http:// www.hqlo.com/content/10/1/137.

Narayan, A., \& Mahajan, S. (2013). The state of opportunities in South Africa: Inequality among children and in the labour market, 2(1). Washington DC: World Bank. http://www.worldbank.org/content/dam/Worldbank/document/Poverty\%2odocume nts/Inequality-in- Focus-April2013.pdf. Accessed 18 May 2015.

Perkins, S. C., Finegood, E. D., \& Swain, J. E. (2013). Poverty and language development: Roles of parenting and stress. Innovations in Clinical Neuroscience, 10(4), 10-19.

Philip, K., Tsedu, M., \& Zwane, M. (2014). The impacts of social and economic inequality on economic development in South Africa. New York: United Nations Development Programme. http://www.za.undp.org/content/dam/south_africa/docs/ Reports/UNDP\%20Inequality\%20South\%20Africa.pdf. Accessed 18 May 2015.

Plumb, J. C. (2011). The impact of social support and family resilience on parental stress in families with a child diagnosed with an Autism Spectrum Disorder. Doctorate in Social Work (DSW) Dissertations, Paper 14. Retrieved from http://repository.upenn.edu/edissertations_sp2/14.

Poverty Trends in South Africa (2017). Poverty Trends in South Africa: An examination of the absolute poverty between 2006-2015. Available online from:www.statssa.co.za.

Reynolds, M. C., Birzer, M., St. John, J., Wells, N., Anderson, B., \& Klein Walker, D. (2015). Family leaders and workforce leadership development. Maternal \& Child Health Journal, 19, 252-256. https://doi.org/10.1007/s10995-014-1617-6.

Samek, D. R., \& Reuter, M. A. (2011). Associations between family communication patterns, sibling closeness, and adoptive status.

Journal of Marriage and Family, 73, 1015-1031. https://doi.org/10.1111/j.17413737.2011.00865.x.

Schrodt, P., \& Ledbetter, A. M. (2007). Communication processes that mediate family communication patterns and mental wellbeing: A mean and co-variance structures analysis of young adults from divorced and non-divorced families. Human Communication Research, 33, 330-356.

Seccombe, K. (2002). 'Beating the odds' versus 'Changing the odds': Poverty, resilience, and family policy. Journal of Marriage and Family, 64, 384-394.

Shannon, D. K., Oakes, K. E., Scheers, N. J., Richardson, F. J., \& Stills, A. B. (2013). Religious beliefs as moderator of exposure to violence in African American adolescents. Psychology of Religion and Spirituality, 5(3), 172-181. https://doi.org/10.1037/aoo30879.

Shin, S. H., Choi, H., Kim, M. J., \& Kim, Y. H. (2010). Comparing adolescents' adjustment and family resilience in divorced families depending on the types of primary caregiver. Journal of Clinical Nursing, 19, 1695-1706. https://doi.org/10.1111/j.1365-2702. 2009.03081.x.

Sixbey, M. (2005). Development of the family resilience assessment scale to identify family 
resilience constructs. University of Florida, Florida: Unpublished doctoral thesis.

Sobolewski, J. M., \& Amato, P. R. (2005). Economic hardship in the family or origin and children's psychological well-being in adult- hood. Journal of Marriage and Family, 67, 141-156.

Statistics South Africa (2012). Census 2011 statistical release (revised) - Po301.4. Pretoria: Statistics South Africa. http://www.statssa.gov. za/publications/Po3014/Po30142011.pdf. Accessed 7 July 2013.

Torres Fernandez, I., Schwartz, J. P., Chun, H., \& Dickson, G. (2013). Family resilience and parenting. In D. S. Becvar (Ed.), Handbook of family resilience. New York: Springer.

Ungar, M. (2010). Families as navigators and negotiators: Facilitating culturally and contextually specific expressions of resilience. Family Process, 49(3), 421-435.

Vermeulen, T., \& Greeff, A. P. (2015). Family resilience resources in coping with childhood sexual abuse. Journal of Child Sexual Abuse, 24, 555-571.

Walsh, F. (2003). Family resilience: A framework for clinical practice. Family Process, 42(1), 1-18.

Walsh, F. (2006). Strengthening family resilience (2nd ed.). New York: The Guilford Press.

Walsh, F. (2012). Family resilience: Strengths forged through adversity. In F. Walsh (Ed.), Normal family processes (4th ed., pp. 399-427). New York: Guilford Press.

Walsh, F. (2016). Strengthening family resilience (3rd ed.). New York: The Guilford Press.

Western Cape Safety Report (2013). Western Cape Government community safety report $2012 / 2013$.

http://www.crimestatssa.com/ provinceselect.php? ShowProvince=Western+Cape. Accessed 6 June 2016.

Windsor, L. C. (2013). Using concept mapping in community-based par- ticipatory research: A mixed methods approach. Journal of Mixed Methods Research, 7(3), 274-293. https://doi.org/10.1177/1558689813479175.

Wood, L. (2016). Community development in higher education: how do academics ensure their community-based research makes a difference? Community Development Journal. https://doi.org/10.1093/ cdj/bsvo68. 